\title{
Australian Journal of Crop Science \\ Steady shallow water table did not decrease leaf expansion rate, specific leaf weight, and specific leaf water content in tomato plants
}

\author{
Mei Meihana ${ }^{1,2}$, Benyamin Lakitan ${ }^{3,4 *}$, Susilawati ${ }^{3}$, M.U. Harun ${ }^{3}$, Laily I. Widuri ${ }^{1}$, Kartika Kartika ${ }^{1}$, \\ Erna Siaga ${ }^{1}$, Haris Kriswantoro ${ }^{1,5}$ \\ ${ }^{1}$ Graduate School, Universitas Sriwijaya, Palembang 30139, Indonesia \\ ${ }^{2}$ STIPER Sriwigama, Palembang 30137, Indonesia \\ ${ }^{3}$ College of Agriculture, Universitas Sriwijaya, Inderalaya 30662, Indonesia \\ ${ }^{4}$ Research Center for Sub-optimal Lands (PUR-PLSO), Universitas Sriwijaya, Palembang 30139, Indonesia \\ ${ }^{5}$ Universitas Palembang, Palembang 30139, Indonesia
}

*Corresponding author: blakitan60@unsri.ac.id

\begin{abstract}
It was presumed that shallow water table restricted leaf growth and some water-related parameters; therefore, they can be used as indicators of plant stress due to the water table condition. Objective of this research was to evaluate morphological stress indicators in tomato plants exposed to shallow water table. The research was conducted in two stages: (1) developing reliable LA estimation model from June to September 2016; as pre-requisite for (2) calculating and evaluating the morphological indicators for stress due to shallow water table treatments, conducted from February to May 2017. Treated plants were placed inside experimental pools. Each treatment was done by partially submerging growing substrate to the targeted water tables at $5 \mathrm{~cm}$ and $10 \mathrm{~cm}$ below surface of the substrate. Untreated control plants were kept outside the pools. Zero-intercept linear model was the selected model for leaf area estimation after evaluating 15 combinations of five regression models and three predictors. Results of this study indicated that steady water table at $5-\mathrm{cm}$ and $10-\mathrm{cm}$ depth did not restrain relative leaf expansion rate (RLER) and there was no significant difference in specific leaf fresh weight (SLFW) and specific leaf water content (SLWC) between treated and untreated plants, measured prior to, during, and after recovery from shallow water table treatments. In conclusion, if position of water table was steady, the shallow water table at 5-cm depth or deeper did not affect tomato growth.
\end{abstract}

Keywords: anaerobic; climate change; growth analysis; leaf area; leaf growth; Lycopersicum esculentum; soil water table; stress indicator; waterlogging; wetland agriculture.

Abbreviations: DAT_days after treatment; DBT_days before treatment; DTI_day treatment initiated; L_leaf length; LA_leaf area; LDW_leaf dry weight; LER_Leaf expansion rate; LFW_leaf fresh weight; LW_length $\mathrm{x}$ width; $\mathrm{R}^{2}$ _coefficient of determination; RLER_relative leaf expansion rate; SLFW_specific leaf fresh weight; SLWC_specific leaf water content; UTC_untreated control; W_leaf width; WT_water table

\section{Introduction}

Climate change is considered as a major challenge in agriculture at present and will even more challenging in the future. The tricky challenges are not on any specific direction of changes, but rested on irregularity and unpredictability of the changes. In the tropical rain forest climate zone, such as in Indonesia, irregularity of annual rain distribution has become more frequently experienced by farmers, causing damage to crops or at least significantly decreasing crop yield. Bailey-Serres et al. (2012) reported that reduction in crop yield due to excess water could be more than 70 percent of potential yield. Both drought and excessive water conditions have been traumatic threats to smallholder farmers.

Excessive water at agricultural land comes at different levels of damaging effect to crops. Submerging and deep flooding conditions for more than a week will leave only a few rice varieties to survive; whereas, most of other food crops could not survive. Waterlogging is good for rice and few aquatic vegetable crops, but most of food and horticultural crops would undergo significant reduction in productivity or worse ending. Even though, damages due to shallow soil water table may be considerably less than those due to submerging and waterlogging, most of farmers are unwilling to cultivate any crops on lands with frequent occurrence of shallow water table.

Among agricultural problems associated with excessive water, less attention has been given to the effect of shallow water table on crop growth and development. Stress condition caused by excessive water could lead to hypoxic soil condition during shallow water table and anoxic condition during waterlogging and flooding occurrences (Sairam et al., 2008; Malik et al., 2015). Soil pores below water table were filled with water; therefore, oxygen for root aerobic metabolism would be deficient. Elzenga and Veen (2010) estimated that diffusion of gasses was 10,000 times slower in water than in air. Thus, in waterlogged soils gas exchange was severely impeded, causing depletion of oxygen 
and accumulation of carbon dioxide produced by microbial and root respiration.

Most of vegetable crops are sensitive to shallow water table. Only a few of vegetable crops have the ability to tolerate or adapt to this unfavorable condition. Shallow water table limits aerobic portion of rhizosphere for roots to uptake essential nutrients. In longer exposure, it can cause death of roots submerged below the water level. At the end, shallow water table could significantly decrease crop growth and yield. Information on how tomato responses to shallow water table in tropical riparian wetland ecosystem is insufficient, specifically on the depth of water table in which tomato plants were able to tolerate and how long tomato plants could withstand such unfavorable soil condition.

The objectives of our study were to develop leaf area estimation model for non-destructively and continuously collecting LA data, for further use in calculating RLER, SLFW and SLWC. These variables (RLER, SLFW, and SLWC) will be evaluated for their appropriateness as indicators of stress intensity in tomato (Lycopersicum esculentum .L) exposed to shallow water table at different depths and durations.

\section{Results and discussion}

\section{Developing and screening LA estimation models}

Based on the coefficient of determination $\left(\mathrm{R}^{2}\right)$, it was revealed that models using single predictor of $\mathrm{L}$ or $\mathrm{W}$ were less reliable for estimating LA in tomato plants than those using LW as predictor, with exception of power regression model using $\mathrm{W}$ as predictor (Table 1). Similar result was reported by Dannehl et al. (2012).

Regular tomato leaf is a compound leaf type. The leaf shape is very complicated. Hareven et al. (1996) described the typical tomato leaf was consisted of a terminal leaflet and several pairs of lateral leaflets, appearing in basipetal order. Both types of leaflet were petiolated and the leaflet blade had serrate margins, notched like a saw with teeth pointing toward the leaf apex. Folioles (F) were appeared inconsistently between leaflets along the rachis or on either side of the petioles. This type of complicated compound leaf has made LA of tomato is difficult to estimate with high accuracy, especially if it is compared to single leaf with regular shape and smooth edge like that of chili pepper.

Of 15 combinations of five regression models and three predictors, only two LA estimation models that indicated empirically significant reliability $\left(R^{2}>0.950\right)$ for estimating tomato LA, i.e. power regression models with $\mathrm{W}$ or $\mathrm{LW}$ as predictors (Table 1). Of the two models, that used LW as predictor exhibited better coefficient of determination $\left(\mathrm{R}^{2}=\right.$ 0.972). The larger the leaf, the lower was the ratio of $\mathrm{L}$ to $\mathrm{W}$ (L/W ratio). Therefore, the power regression model was statistically more appropriate than linier regression model when only L or W was used as predictor. Meanwhile, the quadratic regression tends to overestimate the predicted LA of small leaves if $\mathrm{L}$ was used as predictor and reversely it tends to underestimate LA if $\mathrm{W}$ was used as predictor (Schwarz and Kläring, 2001).

Since the models were purely empirical; therefore, they would be applicable within ranges of $\mathrm{W}<35 \mathrm{~cm}$ and LW < $1,200 \mathrm{~cm}^{2}$ (Fig. 1). It should also be noted that the models tended to slightly under estimated LA toward high end if W was used as predictor. The deviation was less obvious if LW was used as predictor.

Other studies also indicated that linear or zero-intercept linear model was reliable for LA estimation if LW was used as predictor in tomatoes. Blanco and Folegatti (2003) found that linear regression model of LA $=0.347 \mathrm{LW}-10.7$ yielded an $\mathrm{R}^{2}=0.980$; thus, reliable for estimating LA of tomato hybrid variety of Facundo used in their study. Comparably, Carmassi et al. (2007) used F1 of varieties Jama in their study and reported that zero intercept linear regression model of $\mathrm{LA}=0.5 \mathrm{LW}$ settled with lower $\mathrm{R}^{2}$ of 0.884 . In our study, if LW was used as predictor, the $\mathrm{R}^{2}$ were 0.950 for linear and 0.945 for zero-intercept linear models.

Differences in slope and the $\mathrm{R}^{2}$ values between our and other results cannot be confronted between one to another, since there are significant differences in leaf type among tomato varieties. Carmassi et al. (2007) argued that such differences might be caused by cultivation practices and genetic factors that greatly affect the morphology of tomato leaves.

Zero-intercept linear model has stronger argument in estimating LA than those purely empirical models. Geometrical base of the zero-intercept linear model or regression-through-the-origin model has long been recognized. The geometrical bases were (a) if $\mathrm{L}=0 \mathrm{~cm}$ or W $=0 \mathrm{~cm}$, then $\mathrm{LA}=0 \mathrm{~cm}^{2}$; and (b) since leaf area expansion is two dimensional but L/W ratio is not necessarily constant, the use of L or $\mathrm{W}$ individually to estimate LA might not be appropriate. However, LW should has a linear relationship with LA. If the zero intercept linear model of LA $=\beta L W$ is used, the slope [B] is the fraction of a rectangle of $\mathrm{L} \times \mathrm{W}$ occupied by the leaf (Lakitan, 1989; Lakitan et al., 2017).

In this study, the $\mathrm{R}^{2}$ for zero-intercept linear model using LW as predictor was 0.945 (Fig. 2), meaning that 94.5 percent of variability in tomato LA was associated directly with LW. Taking into account the geometrical base of this model; therefore, it is reasonable to use the zero-intercept linear model for estimating LA in tomato plants.

\section{RLER as an indicator of stress due to shallow water table}

The most sensitive signal to indicate hypoxic stress in plant occurs in leaf organ. Hypoxic condition in shallow water table triggered alteration of plant morphology such as decreasing leaf area, reducing leaf expansion rate, and reducing leaf water content (Bradford and Hsiao, 1982; Ashraf, 2012; Aldana et al., 2014). Continuous observation of LA is useful for analyzing plant growth and development during stress condition.

Two LA measurements per day were conducted for differentiating RLER during daytime (diurnal) and night-time (nocturnal). Since leaf expansion in tomato plant occurs within a period of less than 2 weeks, the RLER measurements during stress were started with newly unfolded leaves at initiation of shallow water table treatment. Result of continuous measurements of the diurnal and nocturnal RLER during 10 days of each treatment plus 9 days of recovery is presented in Fig. 3.

These laborious LA measurements lead to interesting findings: [1] under lowland tropical climate conditions, there were significant velocity differences between diurnal and nocturnal RLER. Nocturnal RLER was about 3 times faster than diurnal RLER. The fastest nocturnal RLER was reached at the fifth night; [2] duration of active leaf expansion was less than 10 days; and [3] constant water table at $5 \mathrm{~cm}$ and 10 $\mathrm{cm}$ below substrate surface did not restrain leaf expansion in tomato. Surprisingly, at the fourth day and thereafter, the RLER were higher in shallow water table treated tomato plants than that of control untreated plants (Fig. 3).

Pantin et al., (2011) established the developmental pattern of individual leaf expansion during days and nights in the model 
Table 1. Performance of five leaf area estimation models in tomato using leaf length (L), width (W), and LW as predictors.

\begin{tabular}{llll}
\hline Predictor & Model & Regression equation & $\mathrm{R}^{2}$ \\
\hline \multirow{5}{*}{ Leaf length (L) } & LA $=8.795 \mathrm{~L}-48.73$ & 0.818 \\
& Zero-intercept linear & LA $=6.714 \mathrm{~L}$ & 0.761 \\
& Quadratic & LA $=0.111 \mathrm{~L}^{2}+4.349 \mathrm{~L}-14.62$ & 0.828 \\
& Zero-intercept quadratic & LA $=0.111 \mathrm{~L}^{2}+2.785 \mathrm{~L}$ & 0.827 \\
& Power & LA $=0.828 \mathrm{~L}^{1.627}$ & 0.872 \\
\hline & Linear & LA $=11.13 \mathrm{~W}-63.36$ & 0.900 \\
Leaf Width (W) & Lero-intercept linear & LA $=7.952 \mathrm{~W}$ & 0.809 \\
& Quadratic & LA $=0.328 \mathrm{~W}^{2}+0.327 \mathrm{~W}+5.536$ & 0.940 \\
& Zero-intercept quadratic & LA $=0.900 \mathrm{~W}^{1.688}$ & 0.939 \\
& Power & LA $=0.292 \mathrm{LW}+9.109$ & 0.955 \\
\hline \multirow{5}{*}{ Length $x$ Width (LW) } & LA $=0.307 \mathrm{LW}$ & 0.950 \\
& Linear & LA $=-6 \mathrm{E}-06 \mathrm{LW}^{2}+0.298 \mathrm{LW}+8.374$ & 0.945 \\
& Qero-intercept linear & LA $=-6 \mathrm{E}-06 \mathrm{LW}^{2}+0.335 \mathrm{LW}$ & 0.950 \\
& Zero-intercept quadratic & LA $=0.689 \mathrm{LW} \mathrm{LW}^{0.872}$ & 0.948 \\
& Power & & 0.972 \\
\hline
\end{tabular}
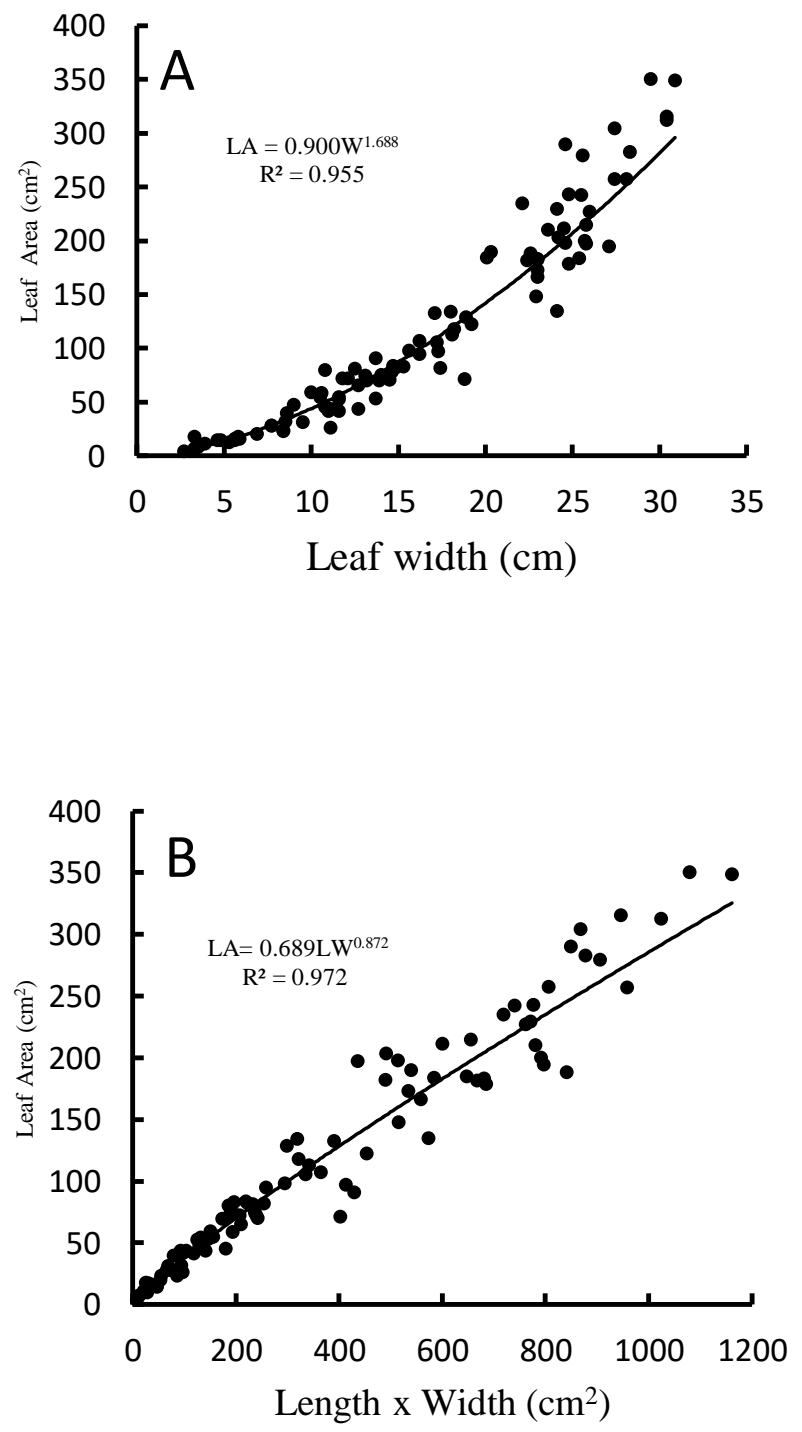

Fig 1. Two most empirically reliable models in leaf area estimation using leaf width (A) and the length $\mathrm{x}$ width (B) as predictors in tomato. 
Table 2. Significance and variation of SLFW and SLWC in tomato prior to, during, and after termination of shallow water table treatment.

\begin{tabular}{lcccc}
\hline \multirow{2}{*}{$\begin{array}{l}\text { Day of } \\
\text { measurement }\end{array}$} & $\begin{array}{c}\text { Calculated F } \\
\text { value }\end{array}$ & $\begin{array}{c}\text { Coefficient of } \\
\text { variation }(\%)\end{array}$ & $\begin{array}{c}\text { Calculated F } \\
\text { value }\end{array}$ & $\begin{array}{c}\text { Coefficient of } \\
\text { variation }(\%)\end{array}$ \\
\hline 4 DBT & $1.06 \mathrm{~ns}$ & 9.747 & $1.14 \mathrm{~ns}$ & 10.034 \\
DTI & $0.94 \mathrm{~ns}$ & 10.345 & $0.64 \mathrm{~ns}$ & 9.973 \\
10 DAT & $0.47 \mathrm{~ns}$ & 14.042 & $0.41 \mathrm{~ns}$ & 14.682 \\
+9 DOR & $1.23 \mathrm{~ns}$ & 26.532 & $1.27 \mathrm{~ns}$ & 28.531 \\
\hline ns = not significantly different among treatments at specific day of measurement. &
\end{tabular}

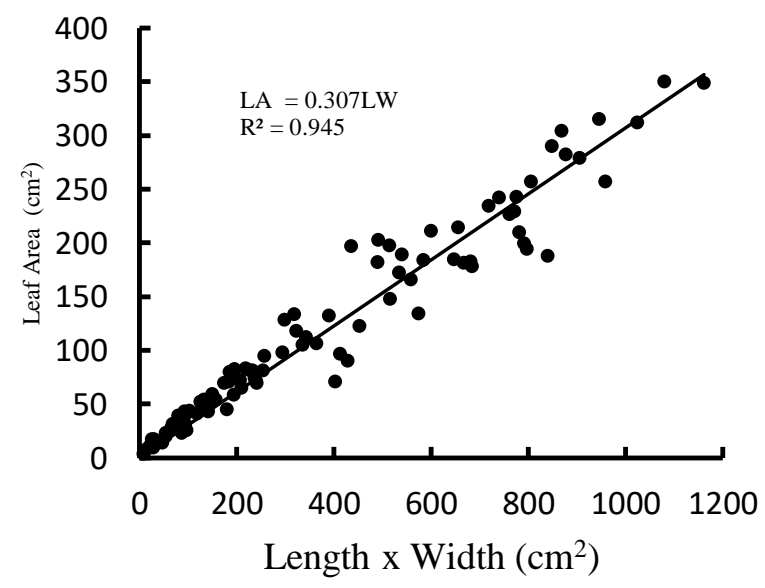

Fig 2. Zero-intercept linear model for leaf area estimation in tomato using LW as predictor.

Table 3. Mean and standard deviation of SLFW and SLWC for each treatment measured prior to, during, and after shallow water table treatment.

\begin{tabular}{lccccc}
\hline \multirow{2}{*}{ Variable } & \multirow{2}{*}{ Treatment } & \multicolumn{4}{c}{ Day of measurement } \\
\cline { 3 - 6 } & & T-4 & T0 & T10 & T10+R9 \\
\cline { 3 - 6 } SLFW $\left(\mathrm{mg} . \mathrm{cm}^{-2}\right)$ & UTC & $43.46 \pm 2.920^{\mathrm{z}}$ & $41.22 \pm 6.974$ & $44.18 \pm 3.586$ & $43.35 \pm 5.355$ \\
& WT-5 & $45.27 \pm 6.021$ & $38.85 \pm 5.070$ & $46.87 \pm 8.119$ & $35.32 \pm 11.23$ \\
& WT-10 & $41.71 \pm 1.737$ & $42.06 \pm 3.206$ & $43.57 \pm 3.944$ & $44.24 \pm 6.531$ \\
\hline \multirow{2}{*}{ SLWC $\left(\mathrm{mg} . \mathrm{cm}^{-2}\right)$} & UTC & $37.78 \pm 2.926$ & $35.90 \pm 5.325$ & $39.09 \pm 3.127$ & $37.27 \pm 4.555$ \\
& WT-5 & $40.17 \pm 5.241$ & $34.22 \pm 4.031$ & $41.01 \pm 7.514$ & $29.79 \pm 12.95$ \\
& WT-10 & $36.94 \pm 1.629$ & $36.45 \pm 2.787$ & $38.03 \pm 3.646$ & $38.19 \pm 5.496$ \\
\hline
\end{tabular}

${ }_{\mathrm{Z}}^{\mathrm{M}} \mathrm{Mean} \pm$ standard deviation

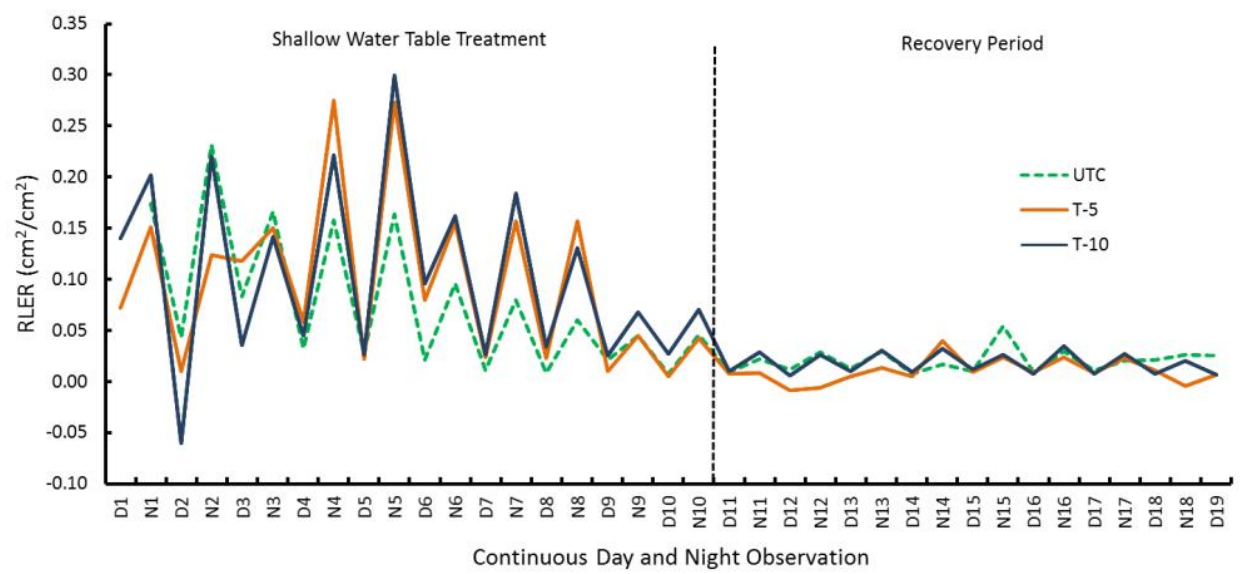

Fig 3. Continuous monitoring of relative leaf expansion rate (RLER) in tomato plants during exposure to shallow water table for 10 days, followed by 9 days of recovery. D was RLER during daytime and N was RLER during night-time observed for 19 consecutive days. Thick grey curvy line is the trend of RLER during water table treatment and recovery period. 
plant Arabidopsis (Arabidopsis thaliana). Leaf expansion occurs mainly at night during the early phases of leaf development. Decreasing of leaf expansion was observed in the daytime. These drops in diurnal RLER have been attributed to an impairment of leaf water potential induced by transpiration. Kalve et al. (2014) also found that maximum RLER was occurring at the earlier phase of leaf development. After 7 to 12 days, the RLER was rapidly declining in Arabidopsis thaliana leaves.

Horchani et al. (2008) reported that root hypoxia below 5$10 \mathrm{~cm}$ under soil surface reduced LA by 53 percent in tomato and the worst effect was observed at 9 days after initiation of the stress treatment.

Based on our RLER data, there was no sign of recovery of the treated tomato plants. However, this finding was inconclusive, since the low RLER during recovery period might not be due to the effect of shallow water table treatment but rather it was due to the natural cause, i.e., the leaves already reached their maximum size. The leaves were 19-day old at end of recovery observation. Asl et al. (2011) observed that during leaf development, a cell proliferation phase, characterized by actively dividing cells, is followed by a cell expansion phase, characterized by cell growth and differentiation. After expansion, cells mature and the final leaf size is reached. Further study is needed, using new leaves at beginning of recovery period in order to settle this issue.

\section{SLFW and SLWC were not affected by shallow water table}

There was no significant difference in SLFW and SLWC measured prior to, during, and after shallow water table treatments. This insignificant difference was partially due to relatively high variability of response among plants after 10 days exposure to shallow water table, and even higher variability among those plants after they were allowed to recover for 9 days. Coefficient of Variation was around 10 percent prior to and more than 14 percent after treatment. Further increased in variability to more than 26 percent was observed after 9 days of recovery (Table 2). In contrast, Saad and Calegaro (2008) found that shallow water table increased soil moisture which, in turn, increased water uptake in bean plants.

This insignificant difference between treated and untreated plants in their response to shallow water table opens opportunity for expanding vegetable cultivation at riparian wetlands in Indonesia. Tomato plants had ability to develop adventitious roots which attributed to its tolerance to excess water conditions (Walter et al., 2004). Adventitious root formation compensated for loss of the original roots due to hypoxic condition below water table (Ezin et al., 2010).

SLFW of all treatments measured prior to, during, and after treatment were all above $35 \mathrm{mg} . \mathrm{cm}^{-2}$ while those of SLWC were all above $29 \mathrm{mg} . \mathrm{cm}^{-2}$ (Table 3). Therefore, based on SLFW and SLWC data, the water contents of both treated and untreated were well above 80 percent. The lowest absolute water content was 84.3 percent, discovered in tomato plants treated with water table at depth of $5 \mathrm{~cm}$ below soil surface, measured after 10 days of treatment plus 9 days of recovery. Above 80 percent water content, the leaves are not at fully turgid condition but well above wilting point.

Shallow water table has been occasionally reported to cause damages to vegetable cultivation at riparian wetlands in Indonesia. However, in this study, fixed water table up to 5 $\mathrm{cm}$ beneath soil surface did not seem to severely affect growth of tomato. Tan (1990) classified tomato as a relatively shallow-rooted plant. Although tomato roots may penetrate beyond $1 \mathrm{~m}$ depth; however, most of the roots are concentrated in the upper $30 \mathrm{~cm}$ of growing substrate.

The depth of water table might not be the main damaging factors, but dynamic fluctuation and unexpected occurrences of the shallow water table does. Roots in the rhizosphere cannot be mobilized. Therefore, in sensitive plants, the roots will die within about one week if exposed to excess water or any other causing factors of hypoxic condition. In order to survive, under shallow water table condition, the plants have to develop adventitious roots above water table line to replace dead primary root system which becomes easily dysfunctional in oxygen-poor soil (Sauter and Steffens, 2014), or to initiate branching of existing roots above water table.

\section{Materials and Methods}

\section{Plant material and growing conditions for leaf area estimation model}

Tomato cultivar of SL1427 was used in this research. Prior to planting, seeds were primed by soaked them for three hours in water and then potentially viable seeds were kept in double-layer wet clothes until radicle was visually drawn-out. Germinated seeds were planted in each cell of seedling trays for three weeks before transplanted into black polyethylene bags filled with mixed growing substrate of soil: manure: compost $(1: 1: 1, \mathrm{v} / \mathrm{v} / \mathrm{v})$. Eight gram of NPK fertilizers were applied per plant and crop protection was implemented as needed.

This research was conducted during dry season, from June 2016 to September 2016 at the Integrated Research Laboratory (10443'48'E; 259'27'S), Universitas Sriwijaya, Palembang.

\section{Development of leaf area estimation model}

Two hundred leaves of tomato were purposively collected, varied from the smallest unfolded leaf to the largest available leaf during vegetative growth stage. Procedures for leaf sampling, allometric measurements, model development and validation as well as screening for a recommended of LA estimation model were according to Lakitan et al., (2017). Five models developed were linear, zero-intercept linear, quadratic, zero-intercept quadratic and power regressions. Three predictors used were $\mathrm{L}, \mathrm{W}$, and LW. These five models combined with three predictors were compared for their accuracy in estimating LA. In addition, geometrical principle and technical simplicity in application of the models were also considered. LA estimation model that indicated empirically significant reliability $\left(R^{2}>0.950\right)$, geometrically sound, and technically simple were chosen as recommended model.

\section{Location, time, and design of water table experiment}

This research was carried out in experimental pools at Macan Kumbang subdistrict ( ${ }^{\circ} 58$ '24.2”S 104 ${ }^{\circ} 43^{\prime} 12.5^{\prime}$ 'E), Palembang, Indonesia, from February 2017 to May 2017. Lay out of the research followed the random block design with three levels of water table depth: $5 \mathrm{~cm}$ below media surface (WT-5); $10 \mathrm{~cm}$ below media surface (WT-10), and untreated control (UTC). Each treatment was replicated 6 times. Water table treatments were applied at early reproductive stage $(50 \%$ of plants population already have at least one flower at full bloom). 


\section{Water table adjustment}

There were 12 experimental pools used for accommodating the two water table treatments, i.e. $5 \mathrm{~cm}$ and $10 \mathrm{~cm}$ below surface of growing media and 6 replications. Dimension of each pool was $2.0 \mathrm{~m}$ length, $1.5 \mathrm{~m}$ width, and $0.25 \mathrm{~m}$ height. Each pool was equipped with outlet valves for setting up depth of water in the pool. Since they are outdoor pools, the valves at specific height for each treatment was kept open throughout treatment period so that rain water will free flow out of each pool for maintaining depth of water inside the pool at constant level.

\section{Measurements of RLER, SLFW, and SLWC}

Continuous measurements of RLER are only possible if there are available LA data collected simultaneously on the same leaves at specified frequency of measurement for a period of time. RLER, SLFW, and SLWC were calculated using estimated LA based of direct measurements of $\mathrm{L}$ and $\mathrm{W}$. In this study, L and W were measured twice for each 24-hour period, i.e. at early morning, started just after sunrise (6.00 to 6.30 a.m.) and at late afternoon, started at half an hour before sunset (5.30 to 6.00 p.m.). It took less than 30 minutes for $\mathrm{L}$ and $\mathrm{W}$ measurements of all sampled plants. Based on $\mathrm{L}$ and W data collected, LA was calculated using the zero intercept linear estimation model. The zero intercept model was chosen for its simplicity, high coefficient of determination, and geometrically-sound.

Measurements of LA both at early morning and late afternoon non-destructively on the same leaves enable to differentiate between diurnal and nocturnal RLER. RLER was calculated based on difference between initial leaf area $\left(\mathrm{LA}_{\mathrm{i}}\right)$ and the next measured leaf area $\left(\mathrm{LA}_{\mathrm{i}+1}\right)$ divided by $\mathrm{LA}_{\mathrm{i}}$. SLFW and SLWC were measured based on LA, leaf fresh weight, and leaf dry weight at four pre-planned sampling dates, i.e., at 4-days before treatment (4 DBT), at day of treatment initiated (DTI), after 10 days of treatment (10 DAT), and 9 days of recovery (+9 DOR). Leaf fresh weight (LFW) was measured by immediately weighting the leaves after excised off the plant. Leaf dry weight (LDW) was measured after the leaves were dried in oven at $105^{\circ} \mathrm{C}$ for 24 hours. SLFW was the ratio of LFW/LA. SLWC was calculated based on difference between LFW and LDW then divided with LA.

\section{Statistical analysis}

Dynamic of night and day RLER were calculated for 19 consecutive days ( 10 days of treatment followed by 9 days of recovery). Analysis of variance was employed for analyzing effects of shallow water table on specific leaf fresh weight (SLFW) and specific leaf water content (SLWC), based on Randomized Block Design (RBD), measured prior to, during, and after shallow water table treatment.

\section{Conclusion}

LA by itself is an important parameter and it also a base for calculation of many secondary parameters in plant growth analysis. RLER, SLFW, and SLWC can be used as indicators for water-related stress. LA data are required in calculation of these parameters. RLER requires series of LA data collected from the same leaf; therefore, non-destructive LA estimation should be used. LW was found as the best predictor and zero-intercept linear regression as recommended model for estimating LA based on its simplicity, high accuracy, and geometrically-sound. Shallow water table at $5 \mathrm{~cm}$ or $10 \mathrm{~cm}$ below surface of growing substrate did not significantly restrain RLER during 10-day period of treatment plus 9-day period of recovery. The shallow water table treatment also did not significantly affect SLFW and SLWC measured at 4 DBT, DTI, 10 DAT, and +9 DOR. Knowing that tomato, and perhaps other shallowrooted vegetable crops, can withstand the stable shallow water table, will open some ideas for cultivating vegetable crops at riparian wetlands by developing small-scale water management system for preventing water table from freely fluctuating.

\section{Acknowledgement}

We deeply appreciate editors of this journal and staffs for their guidance and assistance. Our gratitude also goes to independent reviewers for their comments, suggestions, and corrections to this manuscript. This work was supported by Program Penelitian Unggulan Profesi 2017 Universitas Sriwijaya (SK Rektor No.0570/UN9/PP/2017) and Program BPP-DN of Ministry of Research, Technology, and Higher Education 2015-2018 (SP No. 1265.43/E4.4/2015).

\section{References}

Aldana F, García PN, Fischer G (2014) Effect of waterlogging stress on the growth, development and symptomatology of cape gooseberry (Physalis peruviana L.) plants. Rev Acad Colomb Cienc. 38(149): 393-400.

Ashraf MA (2012). Waterlogging stress in plants: A review. Afr J Agric Res. 7(13): 1976-1981.

Asl LK, Dhondt S, Boudolf V, Beemster GT, Beeckman T, Inzé D, Go vaerts W, De Veylder L (2011) Model-based analysis of Arabidopsis leaf epidermal cells reveals distinct division and expansion patterns for pavement and guard cells. Plant Physiol. 156(4): 2172-2183.

Bailey-Serres J, Seung CL, Erin B (2012) Waterproofing crops: Effective flooding survival strategies. Plant Physiol. 160:1698-1709.

Blanco FF, Folegatti MV (2003) A new method for estimating the leaf area index of cucumber and tomato plants. Hortic Bras. 21(4): 666-669.

Bradford KJ, Hsiao TC (1982) Stomatal behavior and water relations of waterlogged tomato plants. Plant Physiol. 70(5): 1508-1513.

Carmassi G, Incrocci L, Incrocci G, Pardossi A (2007) Nondestructive estimation of leaf area in Solanum lycopersicum L. and gerbera (Gerbera jamesonii H. Bolus). Agr Med. 137: 172-176.

Dannehl D, Rocksch T, Schmidt U (2012) Modelling to estimate the specific leaf area of tomato leaves ('Pannovy'). Acta Hortic. 1099:79-86.

Elzenga JTM, van Veen H (2010) Waterlogging and plant nutrient uptake. In: Mancuso S, Shabala $S$ (eds.) Waterlogging Signalling and Tolerance in Plants (pp. 2335). Springer, Berlin.

Ezin V, Pena RDL, Ahanchede A (2010) Flooding tolerance of tomato genotypes during vegetative and reproductive stages. Braz J Plant Physiol. 22(2): 131-142.

Hareven D, Gutfinger T, Parnis A, Eshed Y, Lifschitz E (1996) The making of a compound leaf: genetic manipulation of leaf architecture in tomato. Cell. 84(5): 735-744.

Horchani F, Aloui A, Brouquisse R, Aschi-Smiti S (2008) Physiological responses of tomato plants (Solanum 
lycopersicum) as affected by root hypoxia. J Agron Crop Sci. 194(4): 297-303.

Kalve S, Fotschki J, Beeckman T, Vissenberg K, Beemster GT (2014) Three-dimensional patterns of cell division and expansion throughout the development of Arabidopsis thaliana leaves. J Exp Bot. 65:6385-6397.

Lakitan, B (1989) Empirical model for estimating leaf area in bean (Phaseolus vulgaris L.). Annu Rep Bean Improv Coop. 32: 19-21.

Lakitan B, Widuri LI, Meihana M (2017) Simplifying procedure for a non-destructive, inexpensive, yet accurate trifoliate leaf area estimation in snap bean (Phaseolus vulgaris L). J Appl Hort. 19(1): 15-21.

Malik AI, Ailewe TI, Erskine W (2015) Tolerance of three grain legume species to transient waterlogging. AoB Plants.7. Plv040. doi:10.1093/aobpla/plv040

Pantin F, Simonneau T, Rolland G, Dauzat M, Muller B (2011) Control of leaf expansion: a developmental switch from metabolics to hydraulics. Plant Physiol. 156(2): 803815 .
Saad JCC, Calegaro JC (2008) Water table effects on bean yield and nitrate distribution in the soil profile. Irriga. 13(3): 355-366.

Sairam RK, Kumutha D, Ezhilmathi K, Deshmukh PS, Srivastava GC (2008) Physiology and biochemistry of waterlogging tolerance in plants. Biol Plantarum. 52(3): 401-412.

Sauter M, Steffens B (2014) Biogenesis of adventitious roots and their involvement in the adaptation to oxygen limitations. In: van Dongen JT, Licausi F (eds.) LowOxygen Stress in Plants (pp. 299-312). Springer, Vienna.

Schwarz D, Kläring, HP (2001) Allometry to estimate leaf area oftomato. J Plant Nutr. 24(8): 1291-1309.

Tan CS (1990) Irrigation scheduling for tomatoes-water budget approach. Factsheet. Agdex/Ontario. Ministery of Agriculture and Food, Toronto.

Walter S, Heuberger H, Schitzler WH (2004) Sensibility of different vegetables to oxygen deficiency and aeration with $\mathrm{H}_{2} \mathrm{O}_{2}$ in the rhizosphere. Acta Hortic. 659: 499-508. 